\title{
Enhancement of UV Photo-catalytic Activity in Greenly Modified Nano-TiO
}

\author{
Fabio G. Santomauro ${ }^{1}$, Sareh Ahmadi ${ }^{2}$, Håkan Rensmo ${ }^{2}$, Daniel L. A. Fernandes ${ }^{3}$, Jacinto Sá ${ }^{3,4, *}$ \\ ${ }^{1}$ Laboratory of Ultrafast Spectroscopy, Swiss Federal Institute of Technology in Lausanne, Switzerland \\ ${ }^{2}$ Department of Physics and Astronomy, Molecular and Condensed Matter Physics, Angstrom Laboratory, Uppsala University, Sweden \\ ${ }^{3}$ Department of Chemistry, Physical Chemistry, Angstrom Laboratory, Uppsala University, Sweden \\ ${ }^{4}$ Institute of Physical Chemistry, Polish Academy of Sciences, Poland
}

Copyright $(2016$ by authors, all rights reserved. Authors agree that this article remains permanently open access under the terms of the Creative Commons Attribution License 4.0 International License

\begin{abstract}
Converting light into chemical bonds is a central motif in energy production. This approach has the advantages of energy production and storage without greenhouse gas emission plus energy produced can be retrieved at anytime. Photosynthesis is nature's way of converting light, water, and $\mathrm{CO}_{2}$ into sugars and oxygen. In optimum conditions, energy-conversion efficiencies up to $7 \%$ can be reached, and $1 \%$ over agricultural crops entire lifecycle. The associated man-made processes are called artificial photosynthesis, and the most notorious process is water splitting, in which water is converted into $\mathrm{H}_{2}$ and $\mathrm{O}_{2}$. We report a green and facile manner to improve $\mathrm{TiO}_{2}$ photo-catalytic activity via nitrogen doping. The method involves soaking $\mathrm{TiO}_{2}$ nano-particles in ammonia solution followed by a heat-treatment. The green credentials stand from the fact that virtually all the adsorbed $\mathrm{NH}_{3}$ is inserted into the structure leading to a close to $100 \%$ atom efficiency. The resultant materials have higher photo-catalytic activity in methanol gas-phase reforming aimed at the production of hydrogen. Nitrogen doping treatment affects moderately the optical properties of $\mathrm{TiO}_{2}$ but the attained activity enhancement was related to a surface modification not optical properties alteration.
\end{abstract}

Keywords Green-synthesis Procedure, Photocatalysis, Hydrogen Production, X-ray Photoelectron Spectroscopy

\section{Introduction}

Converting light into chemical bonds is a central motif in energy production. This approach has the advantages of energy production and storage without greenhouse gas emission plus energy produced can be retrieved at anytime. Photosynthesis is nature's way of converting sunlight, water, and $\mathrm{CO}_{2}$ into sugars and oxygen. In optimum conditions, energy-conversion efficiencies up to $7 \%$ can be reached and
$1 \%$ over agricultural crops entire lifecycle [1] The related man-made processes are called artificial photosynthesis, and the most notorious process is water splitting, in which water is converted into $\mathrm{H}_{2}$ and $\mathrm{O}_{2}$.

Artificial photosynthesis processes can be broken into several elemental steps, namely light harvesting, electron-hole pair formation, charge transport, and catalytic reactions (reductions and oxidations). The maximum solar energy-conversion efficiency achievable with water splitting is $\sim 31 \%$ on single-junction devices under 1 Sun $\left(1 \mathrm{~kW} / \mathrm{m}^{2}\right)$ at AM1.5G illumination, which is comparable to the one attained with photovoltaic cells. Assuming water splitting requires $0.3 \mathrm{eV}$ as a reaction driving force, and given that the energy difference between water oxidation and reduction potentials is $1.23 \mathrm{eV}$, the excitation energy required for the overall process is more than $1.83 \mathrm{eV}(<677 \mathrm{~nm})$, taking into account other energy losses.

Fujishima and Honda published the first significant breakthrough converting light into chemical energy in 1972. They reported the electrochemical photolysis of water assisted by a semiconductor under UV-A radiation [2]. Despite all the scientific advances, it remains a significant challenge to construct a device capable of producing solar fuels, such as hydrogen, at a scale and cost-effective capable of competing with fossil fuels. The US Department of Energy declared that the price of hydrogen must be below $\$ 3.3 \mathrm{~kg}^{-1}$ (including production, delivery and dispensing) in order to compete with gasoline for passenger vehicles. Most developments are based on large band gap semiconductors' $(>3 \mathrm{eV})$, such as $\mathrm{TiO}_{2}$. This is, however, hampered by the need for UV-A (300-400 $\mathrm{nm})$ irradiation to induce charge separation. UV-A accounts for only $4 \%$ of the solar spectrum. Nevertheless, $\mathrm{TiO}_{2}$ remains indisputably the best performing photo-catalyst to date [3], and several efforts are been made to improve visible light absorption, including $\mathrm{TiO}_{2}$ band gap manipulation generally by doping with elements, such as $\mathrm{N}$, $\mathrm{C}$ and $\mathrm{S}[4]$.

In respect to $\mathrm{TiO}_{2}$ nitrogen doping, the most common synthetic procedure involves the thermal treatment of the 
nanopowders in ammonia flow at high temperature $(>$ $\left.500{ }^{\circ} \mathrm{C}\right)[4,5,6,7,8]$. The process yields primarily substitutional modification, i.e., replacement of $\mathrm{O}$ by $\mathrm{N}$ atoms resulting in the formation of new valence states above initial valence band composed of $\mathrm{N} 2 \mathrm{p}$ orbitals [9]. Nonetheless, in certain cases nitrogen doping leads to interstitial nitrogen sites, resulting in the formation of valence states well above the valence band, deep within the gap [10].

Apart of being an energetically demanding process, the aforementioned methodology of doping $\mathrm{TiO}_{2}$ with nitrogen is also an atom inefficient process since the average doping value is ca. $1-2 \%$ after several hours of treatment under continuous flow of $\mathrm{NH}_{3}$, making it unsuitable for mass-production under strict environmental regulations. Greener processes have been proposed, including self-doping [11] and ball milling [12] methodologies. Additional drawback of the current methodology that is routinely overlooked is that the enhancement obtained in the visible range (where pristine $\mathrm{TiO}_{2}$ is inactive) does not counteract the dramatic drop in UV performance, i.e., often photo-catalytic ability and optical absorption are mutually exclusive properties.

Herein, we report a green and facile method to dope $\mathrm{TiO}_{2}$ surface with nitrogen. The methodology yields materials with enhanced photo-catalytic activity in methanol gas-phase reforming under UV irradiation. Gas-phase reforming of alcohols is being considered as a route to upgrade bio-alcohols fractions to carbon free hydrogen and liquid aldehydes, for fuel and chemicals applications, respectively. Alcohol gas-phase reforming follows within the strategy of using liquid substances, such as ammonia, to transporting and releasing hydrogen on the demand. In the present case we use methanol only as a probe molecule to evaluate catalytic abilities since methanol is by itself a commodity and fuel.

\section{Experimental}

\subsection{Synthesis of catalyst}

We used two $\mathrm{TiO}_{2}$ nanopowders, namely pure anatase Hombikat UV100 from Sachtleben Chemie and P25 (mixture of anatase and rutile) from Evonik. The method to dope $\mathrm{TiO}_{2}$ with nitrogen is as it follows. $1.5 \mathrm{~g}$ of $\mathrm{TiO}_{2}(\mathrm{P} 25$ or Hombikat UV 100) was soaked in $15 \mathrm{~mL}$ of $\mathrm{NH}_{3}$ solution (25\% ANALAR NORMAPUR $®)$, and sonicated for $1 \mathrm{~h}$ at room temperature. The samples were filtered, dried, and heated to different temperatures $\left(550\right.$ or $\left.600^{\circ} \mathrm{C}\right)$ for 2 hours in argon flow with a ramp of $10^{\circ} \mathrm{C} / \mathrm{min} .550{ }^{\circ} \mathrm{C}$ was found sufficient to dissociate the pre-adsorbed $\mathrm{NH}_{3}[13,14]$.

To deposit Pt nanoparticles we adopted Cook et al. methodology [15]. Briefly, $0.5 \mathrm{~g}$ of $\mathrm{TiO}_{2}$ (bare or doped) was stirred vigorously for 10 minutes in $40 \mathrm{~mL}$ of deionized water at $\mathrm{pH}$ 6. After that an aqueous solution $(20 \mathrm{~mL})$ containing a predetermined amount of $\mathrm{H}_{2} \mathrm{PtCl}_{6}$ (solution
$20 \%$ of Pt, Alfa Aesar) was added to the mixture. After 30 minutes stirring, a $20 \mathrm{~mL}$ water solution containing $\mathrm{NaBH}_{4}$ with a molar ratio 10 times higher than the amount of the $\mathrm{Pt}$ precursor was added under vigorous stirring. After 10 minutes stirring, the material was washed 2 times with 120 $\mathrm{mL}$ of deionized water and centrifuged (9000 rpm), and 2 times with $120 \mathrm{~mL}$ of Milli-Q water $(18.2 \mathrm{M} \Omega \cdot \mathrm{cm})$. Then the sample was dried in oven at $120^{\circ} \mathrm{C}$ for 8 hours in argon atmosphere. Before testing and analysis, all samples were pulverized in an agate mortar.

\subsection{Characterization of Catalyst}

Surface area measurements were performed by a Micromeritics TRISTAR ${ }^{\circledR}$ _II 3020 surface area analyzer for all the bare samples. The samples were pretreated at $100{ }^{\circ} \mathrm{C}$ and 60 millitorr for 2 hours in an activation system VacPrep 061, to clean and dry completely the surface mainly from adsorbed water molecules. In each analysis, a quantity of sample around $100 \mathrm{mg}$ was used and liquid $\mathrm{N}_{2}$ was used as the cryogenic liquid. For the analysis preparation, an evacuation time of 6 minutes with an evacuation rate of 5 $\mathrm{mmHg} / \mathrm{s}$ was adopted. To extrapolate the surface area, data were collected at relative pressure from 0.05 up to $0.3 \mathrm{bar}$, with an interval of 0.05 .

PXRD patterns were collected with an X'PERT PRO-MPD diffractometer with $\mathrm{Cu} \mathrm{K} \alpha$ radiation and a $\mathrm{Ni}$ filter. Diffraction peaks were recorded in a $2 \theta$ range, from 5 to 70 degrees, with 0.05 degrees intervals. The XRPD spectra were fitted by Quanto, a Rietveld program for quantitative phase analysis [16], and using a Chebyshev polynomial for the background. The sample holder was filled with dry powders, to obtain a flat and uniform surface, as much as possible.

The optical properties of the materials were determined by a UV-Visible reflectance spectrophotometer (Jasco, V-650), equipped with an integrating sphere (ISV-722), employing the Spectralon (a fluoropolymer which has the highest diffuse reflectance of any known material or coating over the ultraviolet, visible, and near-infrared regions of the spectrum) [17], provided by Jasco itself, as a reference not absorbing material. The data interval was $1 \mathrm{~nm}$ and the exchanging of the lamp, between the tungsten lamp and the deuterium one, was at $340 \mathrm{~nm}$. The sample holder was filled with dry powders, to obtain a flat and uniform surface, as much as possible.

XPS measurements using monochromatized Al-Ko at $1486.6 \mathrm{eV}$ were performed on a PHI 5500 system. The base pressure in the analysis chamber was in the low $10^{-8} \mathrm{mbar}$ range. The samples were measured as powders fixed on carbon double-sided tape. Charging was corrected using advantageous C 1s signal (binding energy $284.8 \mathrm{eV}$, equating to $7.2 \mathrm{eV}$ charging in our samples).

TEM images were acquired in a Tecnai F30 ST (FEI) TEM with field emission gun operated at $300 \mathrm{kV}$. We used Z-contrast imaging, generated by HAADF-STEM, to have little or no diffraction effects. This method is ideal for 
tomographic reconstruction because it generates a strong contrast that is related, to a good approximation, to the thickness of the material and the square of its atomic number [18]. SEM images were acquired in a Zeiss ULTRA 55-36-29 SEM and elaborated with SmartSEM V05.04.01.00 software.

\subsection{Catalytic Testing}

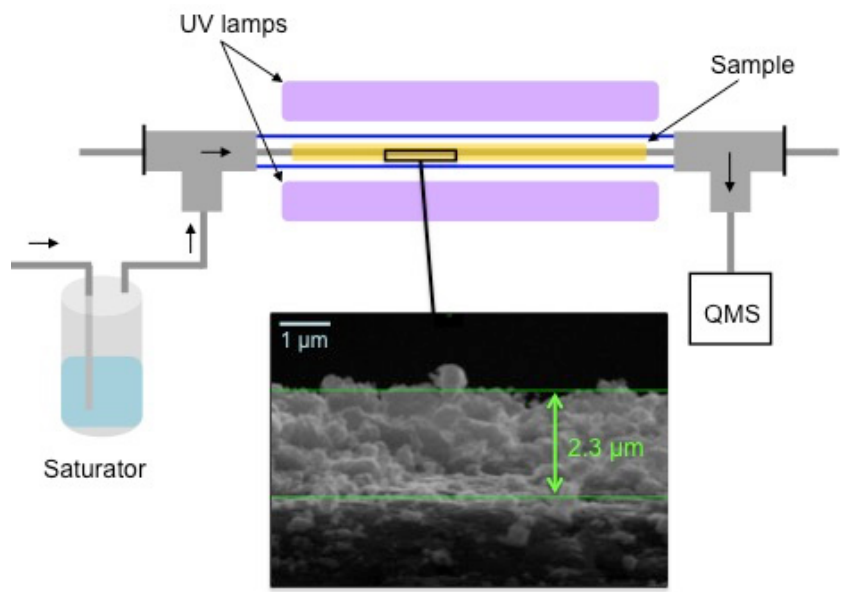

Figure 1. Schematic representation of plug flow reactor used for photo-catalytic reactions. (insert) SEM picture of nanopowder coated on stainless steel bar

The powder materials were tested in photo-catalytic gas-phase reforming of methanol [19] in a plug flow reactor (Fig. 1), composed of UV lamps, saturator, and QMS (quadrupole mass analyser) from Hiden Analytical HPR20. The materials were coated on stainless steel metal bars (Figure 1 SEM insert). A solution containing a sample dissolved in water was sprayed using an airbrush (Airbrush Pro series BD-133) on steel bars (3 $\mathrm{mm}$ of diameter), pre-cleaned by a solution containing $84 \mathrm{~mL}$ of deionized water, $5 \mathrm{~mL}$ of $\mathrm{HF}(>=40 \%)$ and $15 \mathrm{~mL}$ of $\mathrm{HNO}_{3}(65 \%)$, and finally with Milli-Q water $(18.2 \mathrm{M} \Omega \cdot \mathrm{cm})$. The air supply pressure was kept at 3 bar. The material was sprayed at a distance of about $10 \mathrm{~cm}$ in a pulsed mode (10-15 seconds) to avoid the formation of macroscopic drops of water on the surface of the substrate. Before testing, the films were dried completely from water at room temperature. The different materials were tested in the methanol anaerobic photo-oxidation reaction.

Methanol vapour (ANALAR NORMAPUR $\AA$, water content $0.05 \% \max$ ) was carried by an argon flux of 22.6 $\mathrm{mL} / \mathrm{min}$. This flux was the lower value compatible with the QMS requirements and it was chosen to have longer residence time for the reactants in the reactor and therefore higher conversion. The reactor was at room temperature before starting irradiation and at $60{ }^{\circ} \mathrm{C}$, controlled by an air-cooling system, when the lamps were turned on four black light lamps, $12 \mathrm{~W}$ each (maximum emission at $350 \mathrm{~nm}$ ) were used as irradiation sources. The reported values for activity were extracted from QMS data when system stabilized (ca. $1 \mathrm{~h}$ from the start). It should be also mentioned that systems were generally stable upon reaching steady state, at least for the period of measurements (ca. 5h).

\section{Results and Discussion}

Table 1 shows the effect that the applied treatments have in the BET surface area. In the case of P25 samples heat treatment caused minor changes in BET surface area. However in the case of Hombikat UV100, the heat treatment led to a significant decrease in surface area. This is most likely due to an annihilation of some of surface pores because the nominal particle size did not increase according to TEM analysis (figure 2). Another possible explanation could be formation of a rutile phase, however according to PXRD analysis that did not occur in case of Hombikat UV100 (Table 2). In general, none of the treatments had a significant effect in the crystal structure of the materials, according to PXRD analysis (figures 3 and 4). It is known that different $\mathrm{TiO}_{2}$ phases have different activities [20].

Table 1. BET surface area of $\mathrm{TiO}_{2}$ after heat treatment and nitrogen doping.

\begin{tabular}{|c|c|c|c|c|}
\hline \multirow{2}{*}{$\begin{array}{c}\text { BET } \\
\left(\mathrm{m}^{2} / \mathrm{g}\right)\end{array}$} & \multicolumn{2}{|c|}{ Hombikat UV 100 } & \multicolumn{2}{c|}{ P25 } \\
\cline { 2 - 5 } & Pristine & N-doped & Pristine & N-doped \\
\hline-- & 305 & -- & 49 & -- \\
\hline $550^{\circ} \mathrm{C}$ & 82 & 84 & 47 & 45 \\
\hline $600{ }^{\circ} \mathrm{C}$ & 71 & 73 & 46 & 42 \\
\hline
\end{tabular}

Table 2. PXRD of $\mathrm{TiO}_{2}$ after heat treatment and nitrogen doping.

\begin{tabular}{|c|c|c|c|c|c|c|c|c|}
\hline \multirow{2}{*}{$\begin{array}{c}\text { PXRD } \\
(\%)\end{array}$} & \multicolumn{4}{|c|}{ Hombikat UV 100} & \multicolumn{4}{c|}{ P25 } \\
\cline { 2 - 9 } & Pristine & \multicolumn{2}{|c|}{ N-doped } & \multicolumn{2}{c|}{ Pristine } & \multicolumn{2}{c|}{ N-doped } \\
\cline { 2 - 9 } & Anatase & Rutile & Anatase & Rutile & Anatase & Rutile & Anatase & Rutile \\
\hline-- & 100 & 0 & -- & -- & 87 & 13 & -- & -- \\
\hline $550^{\circ} \mathrm{C}$ & 100 & 0 & 100 & 0 & 85 & 15 & 83 & 17 \\
\hline $600{ }^{\circ} \mathrm{C}$ & 100 & 0 & 100 & 0 & 82 & 18 & 76 & 24 \\
\hline
\end{tabular}



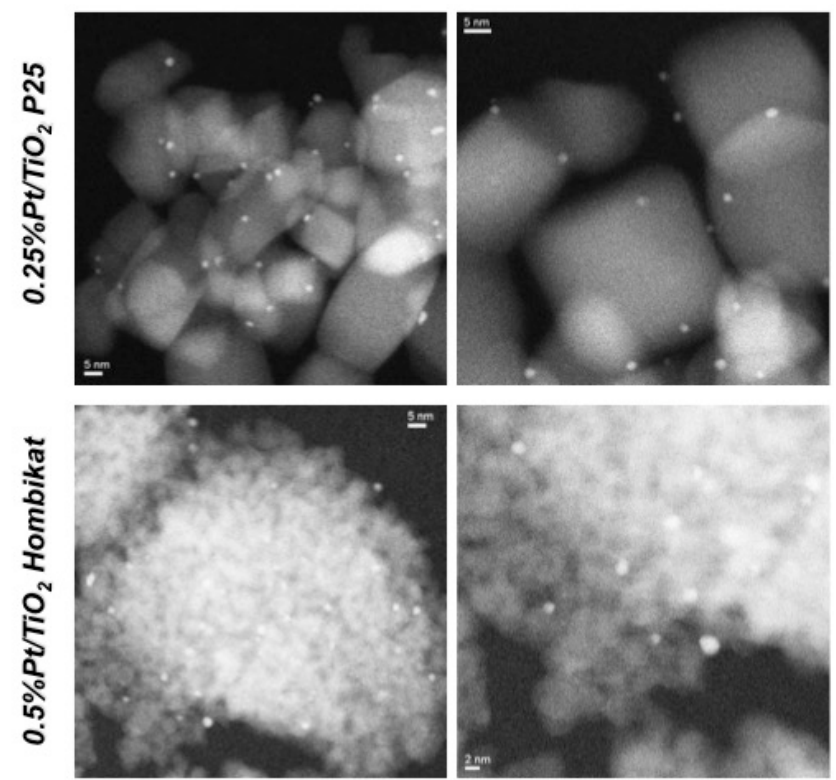

Figure 2. TEM images of $\mathrm{Pt}$ loaded on nitrogen doped $\mathrm{TiO}_{2}$. All the scale bars relate to $5 \mathrm{~nm}$, except picture bottom right that is $2 \mathrm{~nm}$.

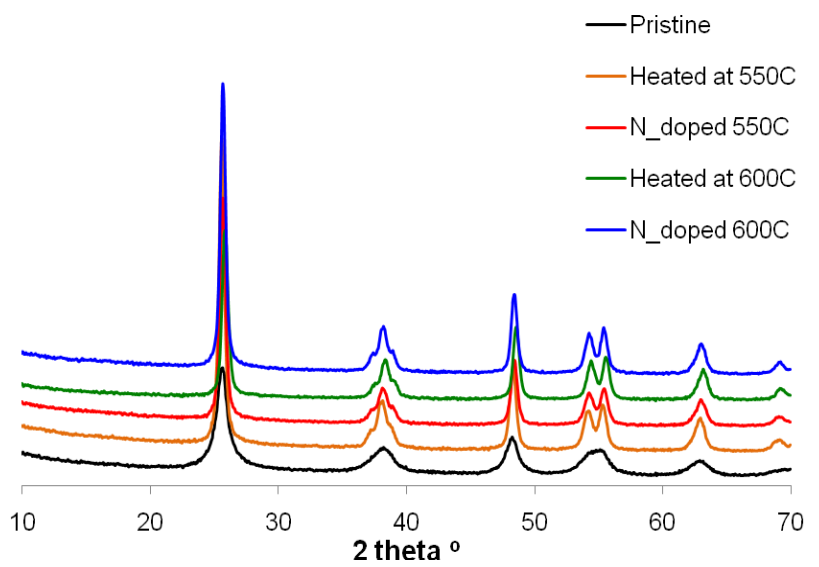

Figure 3. PXRD of $\mathrm{TiO}_{2}$ Hombikat after different treatments.

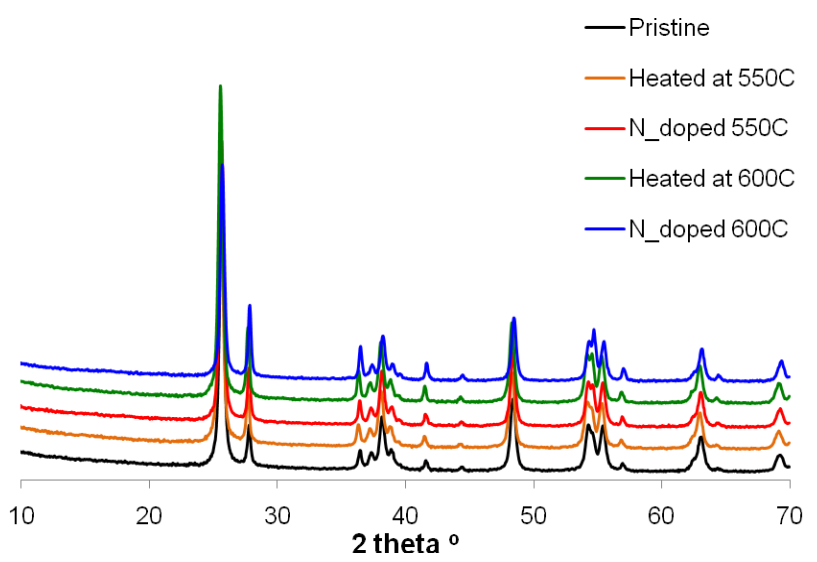

Figure 4. $\mathrm{PXRD}$ of $\mathrm{TiO}_{2} \mathrm{P} 25$ after different treatments.
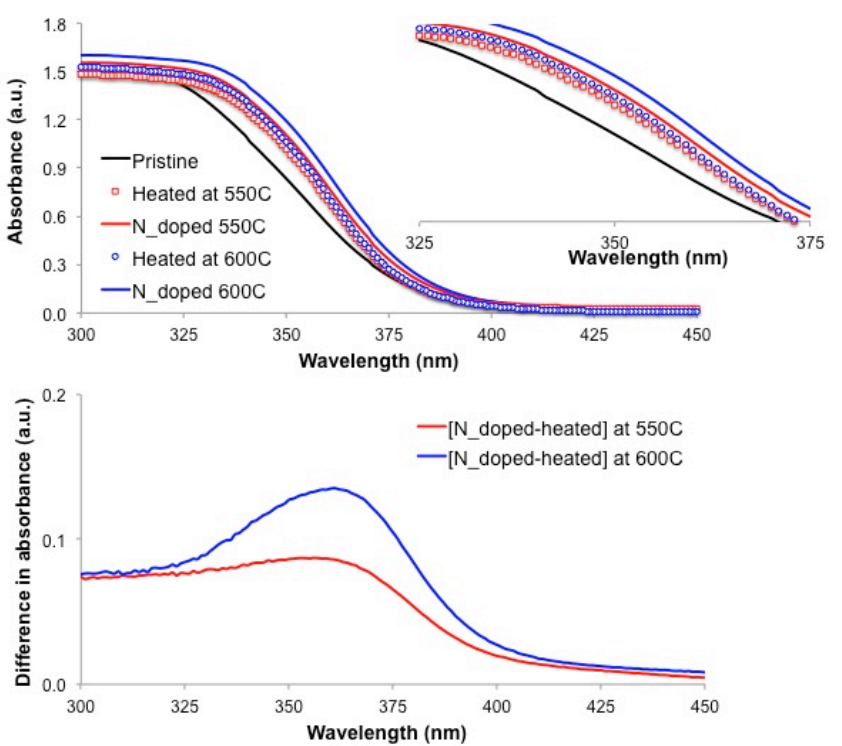

Figure 5. (above) UV-Vis spectra of Hombikat UV100 after heat treatment and nitrogen doping; Insert shows the profiles between 325 and $375 \mathrm{~nm}$ zoomed. (below) Difference in optical absorption between nitrogen doped and pristine sample

Nitrogen doping is commonly used to decrease $\mathrm{TiO}_{2}$ band gap by shifting the valence band edge to higher energy. The effect of heat treatment and nitrogen doping in UV-Vis absorption spectra of Hombikat UV100 is depicted in figure 5 (above). Both heat treatment and nitrogen doping shifted slightly the absorption edge to higher wavelengths, consisting with shortening of the band gap (Table 3). Apart from slight shift, the absorption edge was found to be sharper in the treated samples, which suggests depletion of surface defects. There is also a measurable difference between heated and nitrogen treated samples (figure 5 (below)). Nitrogen doping increased optical absorption in the UV range of about $5-10 \%$, with the biggest gain observed between $325-375 \mathrm{~nm}$, where an increase of about $10 \%$ was measured. Nitrogen doping also extended slightly the absorption in the visible range.

Table 3. Optical band gap estimations for $\mathrm{TiO}_{2}$ after heat treatment and nitrogen doping

\begin{tabular}{|c|c|c|c|c|}
\hline \multirow{2}{*}{$\begin{array}{c}\text { Band gap } \\
(\mathrm{eV})\end{array}$} & \multicolumn{2}{|c|}{ Hombikat UV 100 } & \multicolumn{2}{c|}{ P25 } \\
\cline { 2 - 5 } & Pristine & N-doped & Pristine & N-doped \\
\hline-- & 3.26 & -- & 3.08 & -- \\
\hline $550^{\circ} \mathrm{C}$ & 3.25 & 3.23 & 3.07 & 3.00 \\
\hline $600{ }^{\circ} \mathrm{C}$ & 3.25 & 3.21 & 3.06 & 2.98 \\
\hline
\end{tabular}

Preliminary XPS measurements show that ammonia adsorption prior to heat treatment introduce nitrogen atoms into $\mathrm{TiO}_{2}$ surface because a signal assigned to N1s was detected in narrow scan (figure 6). Since the signal is small and signal-to-noise is low, it is hard to categorically state the position of $\mathrm{N}$ atoms. However, the N1s signal after charged correction was found to be at $398.2 \mathrm{eV}$, commonly assigned to $\mathrm{N}^{3-}$ substituting lattice $\mathrm{O}^{2-}$ [21]. However, we would like 
to reiterate that the signal is rather low to discard the presence of other $\mathrm{N}$-species for example in interstitial positions. The low signal-to-noise also prevents us to estimate the amount of nitrogen dopant in the samples. However no signal was observed for samples that were not treated with $\mathrm{NH}_{3}$, meaning the $\mathrm{N}$ 1s peak is related to materials surface doping.

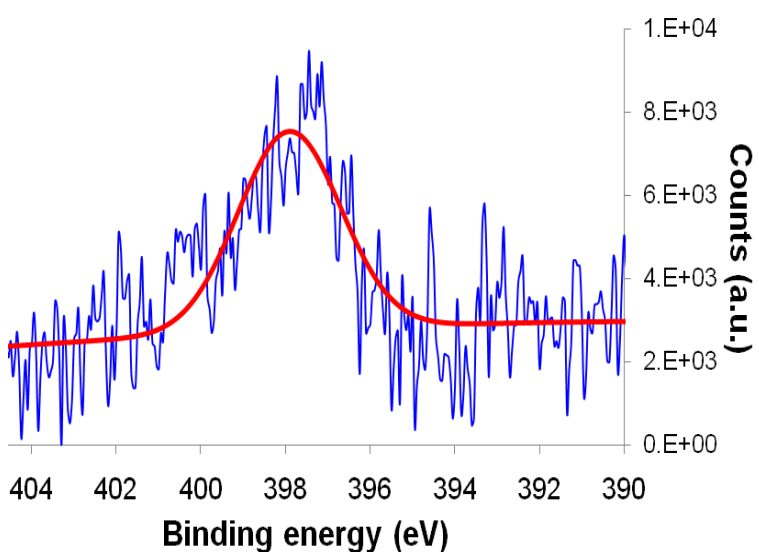

Figure 6. XPS signal of N1s of nitrogen doped Hombikat treated at $600{ }^{\circ} \mathrm{C}$. The data was corrected for charging using advantageous $\mathrm{C} 1 \mathrm{~s}$ signal.

To better compare and determine the differences in photo-catalytic activity due to nitrogen doping, the catalyst loading in the supporting metal bar was optimized and Pt was added to improve $\mathrm{H}_{2}$ evolution capabilities of the catalysts. In terms of optimal catalyst loading on a stainless steel bar, two-sprayed layers was the best loading after normalization to the amount of hydrogen produced per gram of catalyst. The optimal platinum loading depends upon the type of $\mathrm{TiO}_{2}$ used. In the case of P25 the optimal amount of platinum was $0.25 \mathrm{wt} \%$, whereas from Hombikat UV 100 was $0.5 \mathrm{wt} \%$, which corresponds to more or less similar loading per $\mathrm{cm}^{2}$ of material (figure 7). The average particle size of platinum was around 1-2 $\mathrm{nm}$ according to TEM images presented in figure 2.

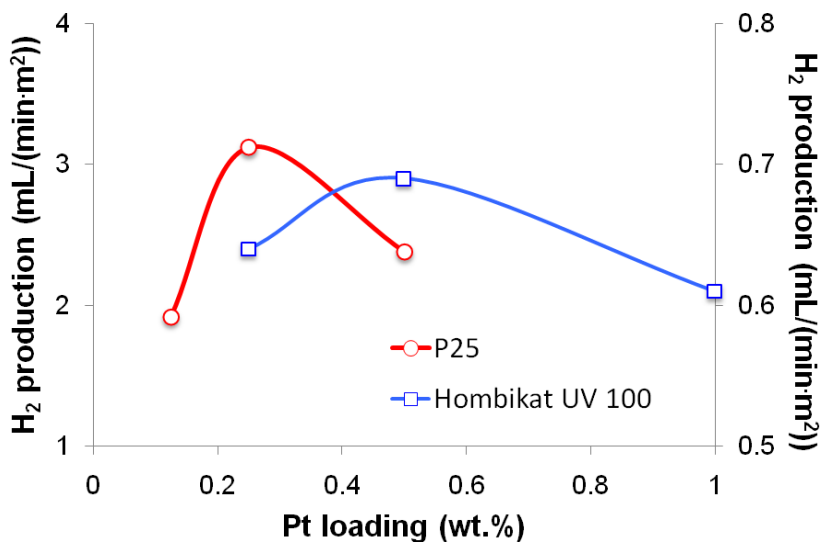

Figure 7. Optimization of platinum loading on $\mathrm{TiO}_{2} \mathrm{H}_{2}$ production has been normalized for the photocatalyst's surface area

Table 4. Comparison of hydrogen evolution during photo-catalytic gas-phase reforming of methanol. $\mathrm{H}_{2}$ production has been normalized for the photocatalysts surface area.

\begin{tabular}{|c|c|c|c|c|c|c|c|c|}
\hline \multirow{2}{*}{$\begin{array}{c}\mathrm{H}_{2} \text { production } \\
\left(\mathrm{mL} /\left(\text { min }^{2}\right)\right)\end{array}$} & \multicolumn{4}{|c|}{ Hombikat UV 100} & \multicolumn{4}{c|}{ P25 } \\
\cline { 2 - 10 } & \multicolumn{2}{|c|}{ Pristine } & \multicolumn{2}{c|}{ N-doped } & \multicolumn{2}{c|}{ Pristine } & \multicolumn{2}{c|}{ N-doped } \\
\cline { 2 - 9 } & bare & $0.5 \% \mathrm{Pt}$ & bare & $0.5 \% \mathrm{Pt}$ & bare & $0.25 \% \mathrm{Pt}$ & bare & $0.25 \% \mathrm{Pt}$ \\
\hline-- & 0.07 & 0.69 & -- & -- & n.d. & 3.12 & -- & -- \\
\hline $550{ }^{\circ} \mathrm{C}$ & 0.15 & 1.87 & 0.20 & 2.14 & n.d. & 2.10 & n.d. & 2.29 \\
\hline $600{ }^{\circ} \mathrm{C}$ & 0.20 & 1.89 & 0.25 & 2.20 & n.d. & 2.38 & n.d. & 3.00 \\
\hline
\end{tabular}

n.d. $\rightarrow$ not detected

Table 5. Comparison of activities on photo-catalytic gas-phase reforming of methanol. $\mathrm{CH}_{3} \mathrm{OH}$ conversion has been normalized for the photocatalyst's surface area.

\begin{tabular}{|c|c|c|c|c|c|c|c|c|}
\hline \multirow{2}{*}{$\begin{array}{c}\mathrm{CH}_{3} \mathrm{OH} \\
\text { conversion } \\
\left(\% / \mathrm{m}^{2}\right)\end{array}$} & \multicolumn{4}{|c|}{ Hombikat UV 100} & \multicolumn{4}{c|}{$\mathrm{P} 25$} \\
\cline { 2 - 9 } & \multicolumn{2}{|c|}{ Pristine } & \multicolumn{2}{|c|}{ N-doped } & \multicolumn{2}{|c|}{ Pristine } & \multicolumn{2}{c|}{ N-doped } \\
\cline { 2 - 9 } & bare & $0.5 \% \mathrm{Pt}$ & bare & $0.5 \% \mathrm{Pt}$ & bare & $0.25 \% \mathrm{Pt}$ & bare & $0.25 \% \mathrm{Pt}$ \\
\hline-- & 4.6 & 4.2 & -- & -- & n.d. & 27.4 & -- & -- \\
\hline $550^{\circ} \mathrm{C}$ & 17.9 & 8.2 & 16.1 & 15.8 & n.d. & 22.0 & n.d. & 26.1 \\
\hline $600{ }^{\circ} \mathrm{C}$ & 21.4 & 13.1 & 20.4 & 16.2 & n.d. & 12.4 & n.d. & 29.5 \\
\hline
\end{tabular}

n.d. $\rightarrow$ not detected 
Tables 4 and 5 show the hydrogen evolution, and methanol conversion for all the materials prepared. It is clear that both the addition of platinum and nitrogen doping improved the hydrogen yields, in particular if one takes into consideration that methanol conversion decreases when platinum is added to the material, i.e., the process selectivity to hydrogen was significantly improved by adding platinum and/or nitrogen doping. The changes in optical absorption cannot account for the catalytic improvement because the central wavelength of the lamps used $(350 \mathrm{~nm})$ is still sufficient to promote the $\mathrm{TiO}_{2}$ band gap transition. However, it should be mentioned that this shift even if it is small could improve charge migration on $\mathrm{TiO}_{2}$ because it puts electrons with higher energy (hotter electrons) in $\mathrm{TiO}_{2}$ conduction band. These electrons can migrate quicker to $\mathrm{Pt}$ nanoparticles, where they are need for hydrogen evolution. Nevertheless the measured improvement is most likely related to $\mathrm{TiO}_{2}$ surface modification. It should be also mentioned that methanol was converted not only to $\mathrm{H}_{2}$ and $\mathrm{CO}_{2}$ but to other chemicals some undetected via QMS but must be presence due to detection of other chemicals. This is a rather complicated reaction with many possible routes but one can state that $\mathrm{H}_{2}$ was by far the main product and thus can be used to evaluate the effect of $\mathrm{N}$-modification. Nevertheless further suited must be carried out to establish reaction mechanisms and kinetics.

Starting by platinum modification on its own, one should expect an increase in hydrogen evolution because according to the Sabatier principle platinum is the best single metal to do proton reduction. However, what was rather unexpected was the drop in methanol conversion since this occurs primarily on $\mathrm{TiO}_{2}$ surface not platinum. Methanol and Pt salt $\left(\mathrm{H}_{2} \mathrm{PtCl}_{6}\right)$ are both mild acids, thus their preferential adsorption site are $\mathrm{TiO}_{2}$ sites with basic in nature. The drop in methanol conversion due to the addition of platinum can be rationalized in terms of competitive adsorption, i.e., platinum titrated some of the available basic sites on $\mathrm{TiO}_{2}$, decreasing their availability for methanol adsorption.

On the other hand, nitrogen doping either maintains or improves methanol conversion in respect to the bare material. $\mathrm{NH}_{3}$ is a mild base and therefore titrates acid sites on $\mathrm{TiO}_{2}$, i.e., does not compete with methanol for adsorption sites. Since in some cases N-doping improves conversion, one is led to believe that this process creates new sites where Pt and methanol can adsorb.

It should be mentioned that this work is in exploratory phase and it was out of the scope to investigate stability. However, the catalysts were found stable for at least $5 \mathrm{~h}$ upon reaching steady state and they could be reused. Even if this does not confirm material stability and reusability, it suggests that formed materials have some resistance against deterioration. Finally, studies on materials stability are difficult to perform using methanol gas-phase reforming because during the first hour of measurements large amount of carbon gets deposited, which are difficult to completely remove via mild oxidation, necessary to evaluate surface doping stability.

\section{Conclusions}

The work reports a green and facile methodology to dope $\mathrm{TiO}_{2}$ with nitrogen. The nitrogen substituted oxygen atoms, which led to a moderate shift of the optical absorption toward the visible range. The resultant materials were found to perform better in the UV photo-catalytic gas-phase reforming of methanol reaction due to surface restructuring. The proposed methodology can be further improved and adapted to gas-phase reforming of other alcohols, in particular bio-alcohols, which would help close the carbon loop in the production of hydrogen from carbonaceous species. The amount of basic sites on $\mathrm{TiO}_{2}$ was found preponderant to catalytic activity. However, these sites are scarce on $\mathrm{TiO}_{2}$. Thus, modifications that can increase their abundance should promote catalytic activity on methanol reforming.

\section{Acknowledgments}

The authors would like to thank Evonik and Sachtleben Chemie for $\mathrm{TiO}_{2}$ samples, which made this work possible.

\section{Abbreviations}

$\mathrm{XPS}=\mathrm{X}$-ray photo electron spectroscopy

$\mathrm{PXRD}=$ Powder X-ray diffraction

TEM $=$ Transmission electron microscopy

HAADF- STEM = high angle annular dark field scanning transmission electron microscopy

SEM $=$ Scanning electron microscopy

$\mathrm{BET}=$ Brunauer, Emmett and Teller surface area

QMS $=$ Quadrupole mass-spectrometer

\section{REFERENCES}

[1] Y. Tachibana, L. Vayssieres, J. R. Durrant, Nat. Photon. 6 (2012) 511.

[2] A. Fujishima, K. Honda, Nature 238 (1972) 37.

[3] K. Hashimoto, H. Irie, A. Fujishima, Japan. J. Appl. Phys. 44 (2005) 8269.

[4] R. Asahi, T. Morikawa, T. Ohwaki, K. Aoki, Y. Yaga, Science 293 (2001) 269.

[5] S. Hoang, S. Guo, N. T. Hahn, A. J. Bard, C. B. Mullins, Nano Lett. 12 (2012) 26.

[6] C. Huang, C. Chen, M. Zhang, L. Lin, X. Ye, S. Lin, M. Antonietti, X. Wang, Nat. Commun. 6 (2015) 7698.

[7] C. Huang, J. Hu, S. Cong, Z. Zhao, X. Qiu, Appl. Catal. B 174-175 (2015) 105.

[8] J. Lynch, C. Giannini, J. K. Cooper, A. Loiudice, I. D. Sharp, R. Buonsanti, J. Phys. Chem. C 119 (2015) 7443. 
[9] J. Szlachetko, J. Sá, CrystEngComm 15 (2013) 2583.

[10] M. Ceotto, L. L. Presti, G. Cappelletti, D. Meroni, F. Spadavecchia, R. Zecca, M. Leoni, P. Scardi, C. L. Biachi, S. Ardizzone, J. Phys. Chem. C 116 (2012) 1764.

[11] S. Wang, J. Xu, H. Ding, S. Pan, Y. Zhang, G. Li, CrystEngComm 14 (2012) 7672.

[12] C. Shifu, C. Lei, G. Shen, C. Gengyu, Chem. Phys. Lett. 43 (2005) 404.

[13] R. Nakamura, T. Tanaka, Y. Nakato, J. Phys. Chem. B 108 (2004) 10617.

[14] H. Irie, Y. Watanabe, K. Hashimoto, J. Phys. Chem. B 107 (2003) 5483.

[15] R. L. Cook, R. C. MacDuff, A. F. Sammells, J. Electrochem.
Soc. 137 (1990) 187.

[16] A. Altomare, M. C. Burla, C. Giacovazzo, A. Guagliardi, A. G. G. Moliterni, G. Polidori, R. Rizzi, J. Appl. Cryst. 34 (2001) 392.

[17] G. T. Georgiev, J. J. Butler, Appl. Opt. 46 (2007) 7892.

[18] M Weyland, Top. Catal. 21 (2002) 175.

[19] M. V. Dozzi, A. Saccomanni, M. Altomare, E. Selli, Photochem. Photobiol. Scie. 2 (2013) 595.

[20] A. Testino, I. R. Bellono, V. Buscaglia, C. Canevali, M. D’Arienzo, S. Polizzi, R. Scotti, F. Morazzoni, J. Am. Chem. Soc. 129 (2007) 3564.

[21] M. Batzill, E. R. Morales, U. Diebold, Phys. Rev. Lett. 96 (2006) 026103. 